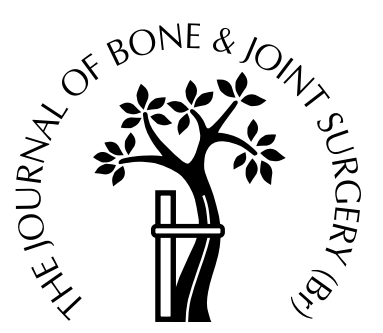

\title{
Test of stability as an aid to decide the need for osteotomy in association with open reduction in developmental dysplasia of the hip
}

\author{
A LONG-TERM REVIEW \\ H. G. Zadeh, A. Catterall, A. Hashemi-Nejad, R. E. Perry \\ From the Royal National Orthopaedic Hospital Trust, Stanmore, England
}

\begin{abstract}
$\mathbf{A}^{\mathrm{n}}$ fter open reduction for developmental dysplasia of the hip (DDH), a pelvic or femoral osteotomy may be required to maintain a stable concentric reduction. We report the clinical and radiological outcome in 82 children (95 hips) with DDH treated by open reduction through an anterior approach in which a test of stability was used to assess the need for a concomitant osteotomy. The mean age at the time of surgery was 28 months ( 9 to 79 ) and at the latest follow-up, 17 years (12 to 25). All patients have been followed up until closure of the triradiate cartilage with a mean period of 15 years ( 8 to 23 ).

At the time of open reduction before closure of the joint capsule, the position of maximum stability was assessed. A hip which required flexion with abduction for stability was considered to need an innominate osteotomy. If only internal rotation and abduction were required, an upper femoral derotational and varus osteotomy was carried out. For a 'double-diameter' acetabulum with anterolateral deficiency, a Pemberton-type osteotomy was used. A hip which was stable in the neutral position required no concomitant osteotomy.

Overall, $86 \%$ of the patients have had a satisfactory radiological outcome (Severin groups I and II) with an incidence of $7 \%$ of secondary procedures for persistent dysplasia including one hip which redislocated. The results were better $(p=0.04)$ in children under the age of two years. Increased leg length on the affected side was associated with poor acetabular development and recurrence of joint dysplasia $(p=0.01)$. The incidence of postoperative avascular necrosis was $7 \%$. In a further $18 \%$,
\end{abstract}

H. G. Zadeh, FRCS Orth, Clinical Fellow in Paediatric Orthopaedics

A. Catterall, MCh, FRCS, Consultant Orthopaedic Surgeon

A. Hashemi-Nejad, FRCS Orth, Consultant Orthopaedic Surgeon

R. E. Perry, RGN, ENB 219 Student

The Royal National Orthopaedic Hospital Trust, Brockley Hill, Stanmore, Middlesex HA7 4LP, UK

Correspondence should be sent to Mr H. G. Zadeh at 59 Apsley House, Finchley Road, London NW8 0NY, UK.

(2) 2000 British Editorial Society of Bone and Joint Surgery 0301-620X/00/19618 \$2.00

VOL. 82-B, No. 1, JANUARY 2000 premature physeal arrest was noted during the adolescent growth spurt (Kalamchi-MacEwen types II and III). Both of these complications were also associated with recurrence of joint dysplasia $(p=0.01)$. Studies with a shorter follow-up are therefore likely to underestimate the proportion of poor radiological results.

J Bone Joint Surg [Br] 2000;82-B:17-27.

Received 3 November 1998; Accepted after revision 29 March 1999

Late presentation and failure of conservative treatment are the main indications for open reduction in developmental dysplasia of the hip (DDH). A number of surgical approaches have been described. We favour the anterior route since it allows good exposure and access to the obstructing tissues, especially in the older child. Simultaneous capsular plication and pelvic osteotomy may be carried out when required. A pelvic or femoral osteotomy may be needed to maintain a stable concentric reduction after open reduction. The choice between these procedures may be controversial and determined by the operating surgeon's experience and training. We have pursued a selective approach with the decision based on a test of stability which is carried out at the time of the open reduction.

We present our experience with this method, the technical details and report the long-term results. We have observed that the radiological outcome deteriorated in a significant number of patients during the adolescent growth spurt, mainly because of premature physeal arrest. Therefore we describe only those patients who were skeletally mature at the latest follow-up.

\section{Patients and Methods}

We have reviewed the clinical and radiological outcome of 82 children with 95 abnormal hips (13 bilateral) presenting to The Children's Unit of the Royal National Orthopaedic Hospital from 1975 to 1989 . They were treated by open reduction through an anterior approach with a concomitant osteotomy based on a test of stability. The first author (HGZ) reviewed $45 \%$ of the cases in a special research clinic. The data for the remainder were collected, retrospectively, from the clinical notes and radiographs. In three 
Table I. The Commission for the Study of Hip Dysplasia (Tönnis) ${ }^{1}$ classification

\begin{tabular}{ll}
\hline Grade & Criteria \\
\hline I & Capital femoral epiphysis medial to Perkins' line \\
II & Capital femoral epiphysis lateral to Perkins' line but below the level of the superior acetabular rim \\
III & Capital femoral epiphysis at the level of the superior acetabular rim \\
IV & Capital femoral epiphysis above the level of the superior acetabular rim \\
\hline
\end{tabular}

Table II. Severin's classification for radiological grading of hip dysplasia ${ }^{2}$

\begin{tabular}{llll}
\hline Group & Criteria & $\begin{array}{l}\text { Centre-edge angle } \\
\text { (degrees) }\end{array}$ & $\begin{array}{l}\text { Age range } \\
\text { (yr) }\end{array}$ \\
\hline I & Normal hip & $>15$ & 5 to 13 \\
& & $>20$ & $>14$ \\
II & Concentric reduction of the joint with deformity & $>15$ & 5 to 13 \\
& of the femoral neck, head or acetabulum & $>20$ & $>14$ \\
III & Dysplasia but no subluxation & $<15$ & 5 to 13 \\
& & $<20$ & $>14$ \\
IV & Subluxation & & \\
V & Articulation with false acetabulum & & \\
VI & Redislocation & & \\
\hline
\end{tabular}

Table III. The Kalamchi and MacEwen classification for $\mathrm{AVN}^{3}$

\begin{tabular}{ll}
\hline Type & Criteria \\
\hline I & Changes confined to the ossific nucleus \\
II & Type I plus lateral physeal damage (coxa valga) \\
III & Type I plus central physeal damage (coxa brevis) \\
IV & Total damage to the head and physis \\
V & Unclassifiable \\
\hline
\end{tabular}

patients the up-to-date clinical and radiological outcomes were obtained from their local hospitals since they were unable to attend our clinic. Patients referred for revision surgery, or with underlying neuromuscular conditions such as spina bifida or cerebral palsy, have been excluded. Five patients were lost to follow-up and were also excluded.

There were 15 boys and 67 girls with a mean age at the time of operation of 28 months ( 9 to 79). Of the 95 hips, 51 were in patients aged less than two years at the time of surgery, 30 were aged between two and four years and 14 were over four years of age. All the hips have been followed up until skeletal maturity as defined by the closure of the triradiate cartilage. The mean age at the latest followup was 17 years (12 to 25 ) with a mean follow-up period of 15 years (8 to 23 ).

The indication for surgery in 59 hips (62\%) was failure of conservative treatment and in $36(38 \%)$ late presentation ( $>2$ years). When conservative treatment had failed in children under the age of one year, open reduction was delayed until about 11 to 12 months of age, unless the child was large and the femoral capital epiphysis visible on radiographs. Preoperative arthrography was carried out in 23 hips (24\%). The severity of the dysplasia, at presentation, was graded according to the system published by the Commission for the Study of Hip Dysplasia ${ }^{1}$ (Table I); 35 hips were grade II (37\%), 32 grade III (34\%) and 28 grade IV $(29 \%)$. Severin's classification ${ }^{2}$ was used for the radio- logical grading of dysplasia at the latest follow-up (Table II). For avascular necrosis (AVN), the system of Kalamchi and MacEwen ${ }^{3}$ was used (Table III). The operation was carried out after at least one week of skin traction. Table IV lists the numbers and types of procedures undertaken and the mean age in each group. The chi-squared test with Yates' correction was used for statistical analysis.

Operative technique. All the hips were operated on by the senior author (AC) using a modified Smith-Petersen approach through an incision below the iliac crest. ${ }^{4,5}$ The iliac apophysis was split and the iliac wing exposed subperiosteally. The straight and reflected heads of rectus femoris were released and the iliopsoas tendon divided close to its attachment to the lesser trochanter. The capsule of the hip was opened parallel to its attachment extending well into the false cavity. The cavity of the acetabulum was cleared of soft tissue, including the ligamentum teres. The inferior capsule and transverse ligament were divided. The femoral head was gently reduced into the acetabulum without tension. At this stage a 'test of stability' was carried out before the closure of the joint capsule.

Test of stability. The aim is to identify the position of maximum stability of the hip. The appropriate osteotomy can then be carried out when necessary to achieve stable concentric reduction in the neutral weight-bearing position. We considered stable open reduction to be present when the hip remained reduced with axial loading with the leg in $30^{\circ}$ of flexion, $30^{\circ}$ of internal rotation and $30^{\circ}$ of abduction. The various components of this position were then removed sequentially, beginning with flexion, to identify the position in which the leg must be placed for maximum stability (Fig. 1). There were six main findings:

Hip stable in neutral position. This requires no further reconstruction and a simple open reduction with capsular repair will suffice. This was uncommon in our experience, accounting for only two hips $(2 \%)$. 


\section{Stable in neutral position}

1

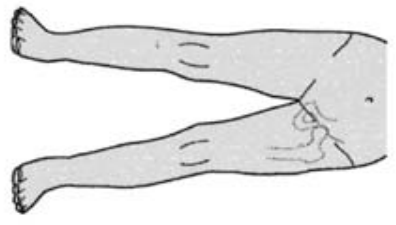

Stable in internal rotation and abduction

2

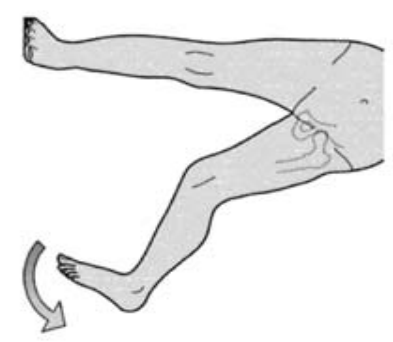

Stable in flexion

3

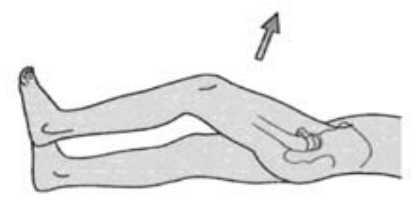

4

Stable in flexion, internal rotation and abduction

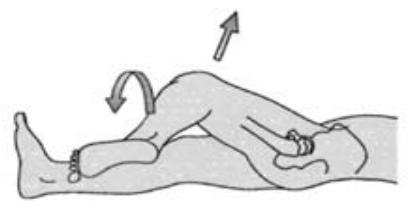

Double-diameter acetabulum with anterolateral acetabular deficiency

5
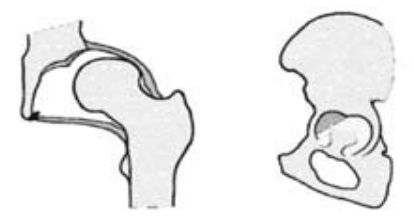

No additional osteotomy required

\section{Derotational and varus femoral osteotomy}
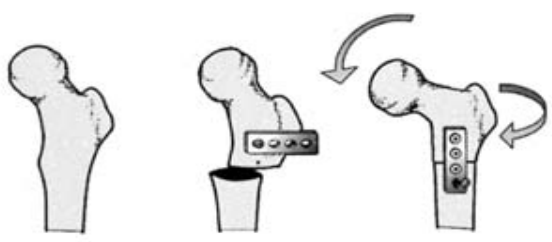

Innominate osteotomy
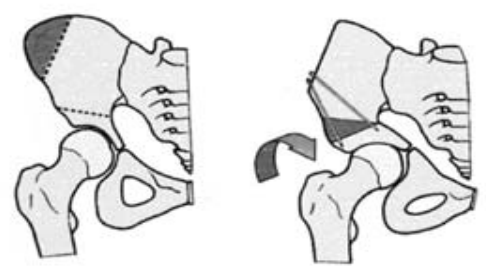

Innominate and derotational varus femoral osteotomy
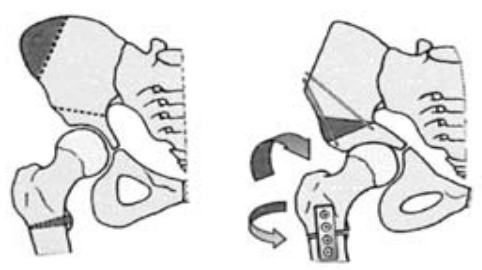

\section{Pemberton osteotomy}
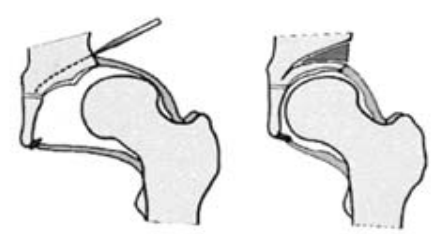

Fig. 1

Diagram of the test of stability (modified from: Catterall A. Operations for congenital dislocation of the hip. In: Bentley G, Greer RB III, eds. Rob and Smith's operative surgery: orthopaedics. Fourth edition. London: Chapman and Hall Medical, 1991:870-99). 
Table IV. Primary operations performed

\begin{tabular}{lcl}
\hline Operation & Number of hips (\%) & $\begin{array}{l}\text { Mean age } \\
(\mathbf{m t h})\end{array}$ \\
\hline Open reduction & $2(2)$ & 19 \\
Open reduction + femoral osteotomy & $63(66)$ & 21 \\
Open reduction + innominate osteotomy & $13(14)$ & 32 \\
Open reduction + innominate + femoral osteotomy & $13(14)$ & 49 \\
Open reduction + Pemberton \pm femoral osteotomy & $4(4)$ & 64 \\
\hline
\end{tabular}

Hip stable in internal rotation and abduction. This is an indication for an upper femoral varus and derotational osteotomy and was the most common finding, especially in the younger age group (63 hips, 66\%; Table IV). The femoral osteotomy was carried out through a separate lateral incision two to four weeks after open reduction. This time was chosen in the hope of reducing the incidence of AVN, as recommended by Tönnis. ${ }^{1,6}$

Hip stable in flexion and abduction. This is an indication for an innominate osteotomy which was carried out at the time of the open reduction. A total of 13 hips (14\%) required this procedure. On average the patients tended to be older than those in the two previous groups (Table IV). The technique was as described by Salter and Dubos.

Hip stable in flexion, internal rotation and abduction. After open reduction and innominate osteotomy, if further internal rotation or abduction was required to maintain stability, an upper femoral derotational or varus osteotomy was added two to four weeks later. This was required in 13 hips (14\%), all in patients in the older age group (Table IV).

'Double-diameter' acetabulum with anterolateral acetabular deficiency. This is an indication for a Pemberton-type osteotomy ${ }^{8}$ and was carried out in four children at the time of the open reduction. In three hips a further upper femoral osteotomy was also necessary.

Tight reduction. When the femoral head could not be reduced without tension with the leg in the neutral position, a femoral shortening osteotomy was carried out to reduce the likelihood of AVN. Depending on the findings of the test of stability a varus or derotational element was also added. These children tended to be in the older age group with a high dislocation. Five hips (5\%) required this operation.

After testing for stability and the appropriate osteotomy, the capsule was repaired and plicated. The wound was closed in layers. The reduction was confirmed radio-
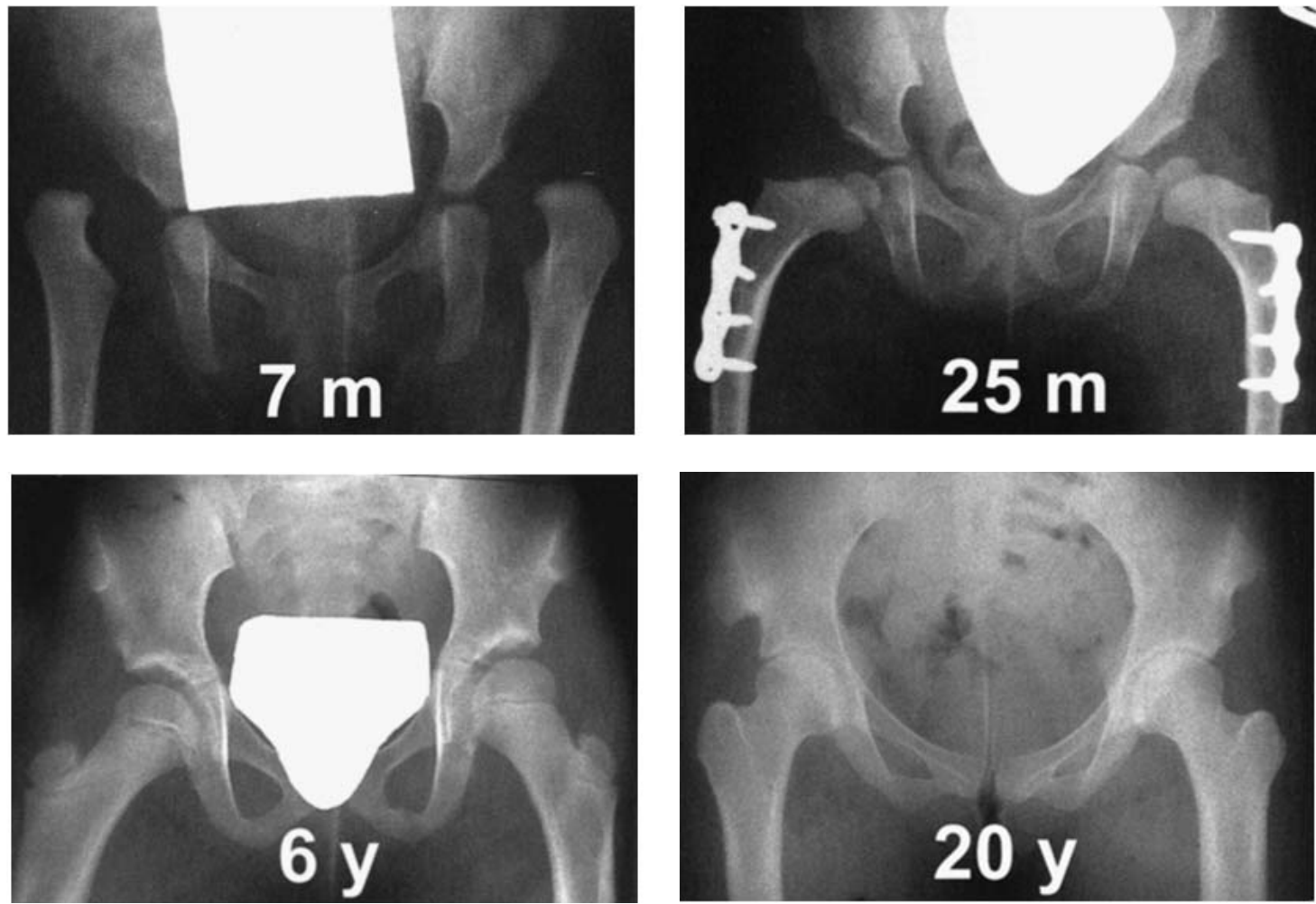

Fig. 2

Serial radiographs of a seven-month-old girl who presented with bilateral DDH. After failure of conservative treatment, she was treated by bilateral open reduction and upper femoral varus and derotational osteotomies at the age of 12 months. Satisfactory radiological and clinical outcomes have been achieved at skeletal maturity (Severin group I). 
Table V. Radiological outcome for the 95 hips by number and percentage

\begin{tabular}{llllll}
\hline & \multicolumn{2}{l}{ Grade } & & & \\
\cline { 2 - 5 } Classification & I & II & III & IV & Total \\
\hline Severin & $33(34.7)$ & $49(51.6)$ & $3(3.2)$ & $10(10.5)$ & \\
Kalamchi-MacEwen & & & & & \\
Preoperative AVN & 1 & 1 & 1 & 2 & $5(5)$ \\
Postoperative AVN & 0 & 1 & 2 & 3 & $6(7)$ \\
Premature physeal arrest & 0 & 9 & 7 & 0 & $16(18)$ \\
\hline
\end{tabular}

Table VI. Radiological outcome for the 95 hips according to the various subgroups

\begin{tabular}{|c|c|c|}
\hline & $\begin{array}{l}\text { Severin I and II } \\
\text { (\% of hips) }\end{array}$ & $\begin{array}{l}\text { Postoperative AVN } \\
\text { or premature physeal } \\
\text { arrest ( } \% \text { of hips) }\end{array}$ \\
\hline \multicolumn{3}{|c|}{ Age (in years) } \\
\hline$<2$ & 94 & 16 \\
\hline 2 to 4 & 80 & 30 \\
\hline$>4$ & 71 & 43 \\
\hline $\mathrm{p}$ value & 0.04 & 0.09 \\
\hline \multicolumn{3}{|c|}{ Tönnis grade } \\
\hline 2 & 91 & 9 \\
\hline 3 & 81 & 30 \\
\hline 4 & 86 & 36 \\
\hline $\mathrm{p}$ value & 0.48 & 0.04 \\
\hline \multicolumn{3}{|c|}{$\begin{array}{l}\text { AVN or premature } \\
\text { physeal arrest }\end{array}$} \\
\hline No & 93 & \\
\hline Yes & 70 & \\
\hline $\mathrm{p}$ value & 0.01 & \\
\hline \multicolumn{3}{|c|}{ Long-leg dysplasia } \\
\hline No & 90 & \\
\hline Yes & 58 & \\
\hline $\mathrm{p}$ value & 0.01 & \\
\hline
\end{tabular}

logically and a hip spica applied for nine to ten weeks. After removal of plaster, no bracing was used and the child was allowed to bear weight fully.

\section{Results}

Overall outcome. In our series, $86 \%$ of the hips had a satisfactory radiological outcome (Severin groups I and II) (Fig. 2). Children under the age of two years appeared to do better than those who were older. Table V summarises the main radiological results. In Table VI the results are shown according to the various subgroups.

Clinical assessment was made according to the modified Severin grading ${ }^{9}$ (Table VII); 86 hips (91\%) were considered as having an excellent clinical outcome (grade 1), one as a good result (grade 2) and eight had intermittent pain or a noticeable limp and were classified as grade 3 .
There were no hips in grade 4. This situation may change in the future in hips with an asymptomatic but poor radiological outcome because of the onset of premature degenerative disease.

AVN and premature physeal arrest. Most type-II and type-III abnormalities of Kalamchi and MacEwen ${ }^{3}(76 \%)$ only became apparent after the adolescent growth spurt, and they presented as premature physeal arrest (Figs 3 to 5). In these hips we did not observe any significant avascular changes during the early postoperative years. We consider this subgroup to be a separate clinical entity from the hips presenting with AVN soon after surgical intervention. In five hips the AVN was present before open reduction and was probably caused by previously unsuccessful conservative treatment. These hips were excluded from the analysis of rates of postoperative AVN or premature physeal arrest. The incidence of the former was $7 \%$ and of the latter $18 \%$. Both of these complications were associated with an unsatisfactory radiological outcome (Severin groups III and IV) and recurrence of joint dysplasia $(\mathrm{p}=0.01)$.

Complications. Table VIII lists the main postoperative complications, excluding AVN and premature physeal arrest, and the number of hips requiring secondary procedures for the correction of these problems. In 13 hips (14\%) the final radiological outcome was unsatisfactory (Figs 5 and 6). There were seven operations for correction of recurrent joint dysplasia (7\%), including one hip which redislocated. None of these cases have had a satisfactory final radiological outcome. Another notable complication in 12 hips was an increase in leg length of more than $1.5 \mathrm{~cm}$ on the affected side (Fig. 6). We refer to this condition as long-leg dysplasia. All of these hips had a femoral osteotomy in conjunction with their open reduction. Innominate osteotomy alone did not result in long-leg dysplasia. In five hips, the increase in leg length was associated with recurrence of joint dysplasia. Four were treated by a varus shortening osteotomy but in the long term this did not fully reverse the dysplastic features (Fig. 6).

Table VII. Clinical evaluation, modified Severin grading ${ }^{9}$

\begin{tabular}{lll}
\hline Grade & Criteria & Number of hips \\
\hline 1 & No pain, no limp, unlimited endurance & 86 \\
2 & No pain, slight limp, slight restriction of endurance & 1 \\
3 & Occasional pain, noticeable limp, endurance moderately restricted & 8 \\
4 & Regular pain, marked limp, severe restriction of endurance & 0 \\
\hline
\end{tabular}



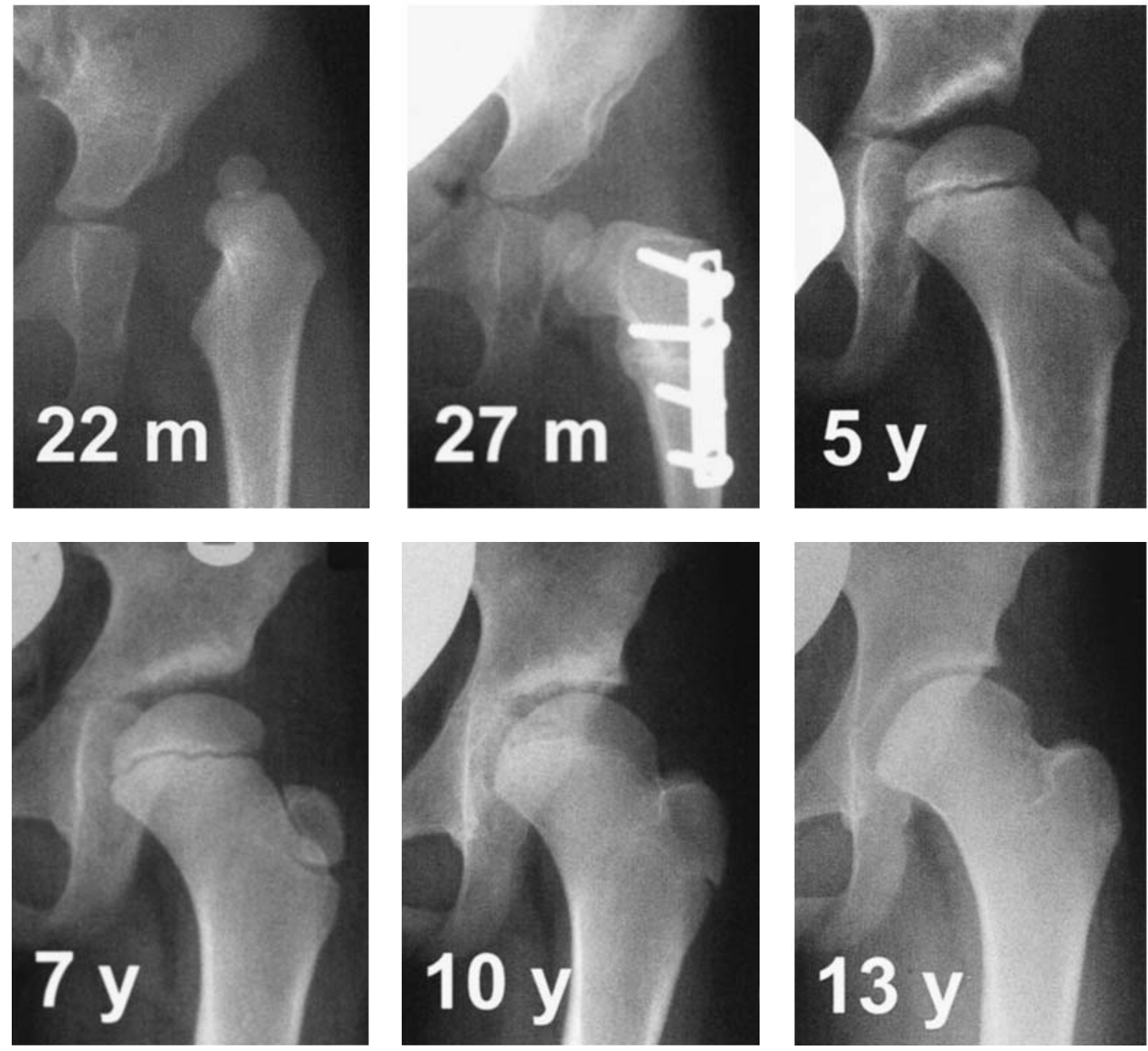

Fig. 3

Serial radiographs of a 22-month-old girl who presented with unilateral left DDH. After failure of conservative treatment, she was treated by an open reduction and upper femoral varus and derotational osteotomy at the age of 24 months. Early radiographs show no clear evidence of AVN. Radiographs at ten years of age show lateral physeal tethering and growth arrest. At skeletal maturity there is moderate deformity of the femoral neck with coxa valga. The joint dysplasia was graded as Severin group II.

A positive Trendelenberg gait and leg shortening on the affected side were associated with type-IV AVN. Four hips required further surgery to correct these problems. A valgus extension osteotomy was carried out in two, distal trochanteric transfer in one and distal femoral epiphysiodesis on the contralateral side in one. The eight distal femoral greenstick fractures all occurred during mobilisation after the spica had been removed. This did not result in any longterm sequelae.

\section{Discussion}

We have presented a long-term review of a series of children with DDH treated surgically. Most were under the age of four years at operation. In the long term, the age at operation appears to be a significant prognostic factor with 94\% achieving an acceptable radiological result when the procedure was undertaken under the age of two years. This decreased to $80 \%$ when it was carried out between two and four years and to $71 \%$ when aged over four years. There was a lower incidence of AVN and late growth disturbances in the group under the age of two years.

After open reduction for DDH, the maintenance of a concentric stable reduction in the neutral position of weight-bearing is paramount if a satisfactory long-term outcome is to be achieved. It is widely accepted that a hip which remains concentrically reduced can stimulate normal development of the joint and in this environment the dysplastic features will undergo spontaneous resolution. ${ }^{10}$

We believe that the test of stability used in our series at the time of open reduction can help the clinician to decide whether a further osteotomy is required and whether it should be carried out in the pelvis, upper femur or both. We argue that, if reconstructive surgery is required, it should be 

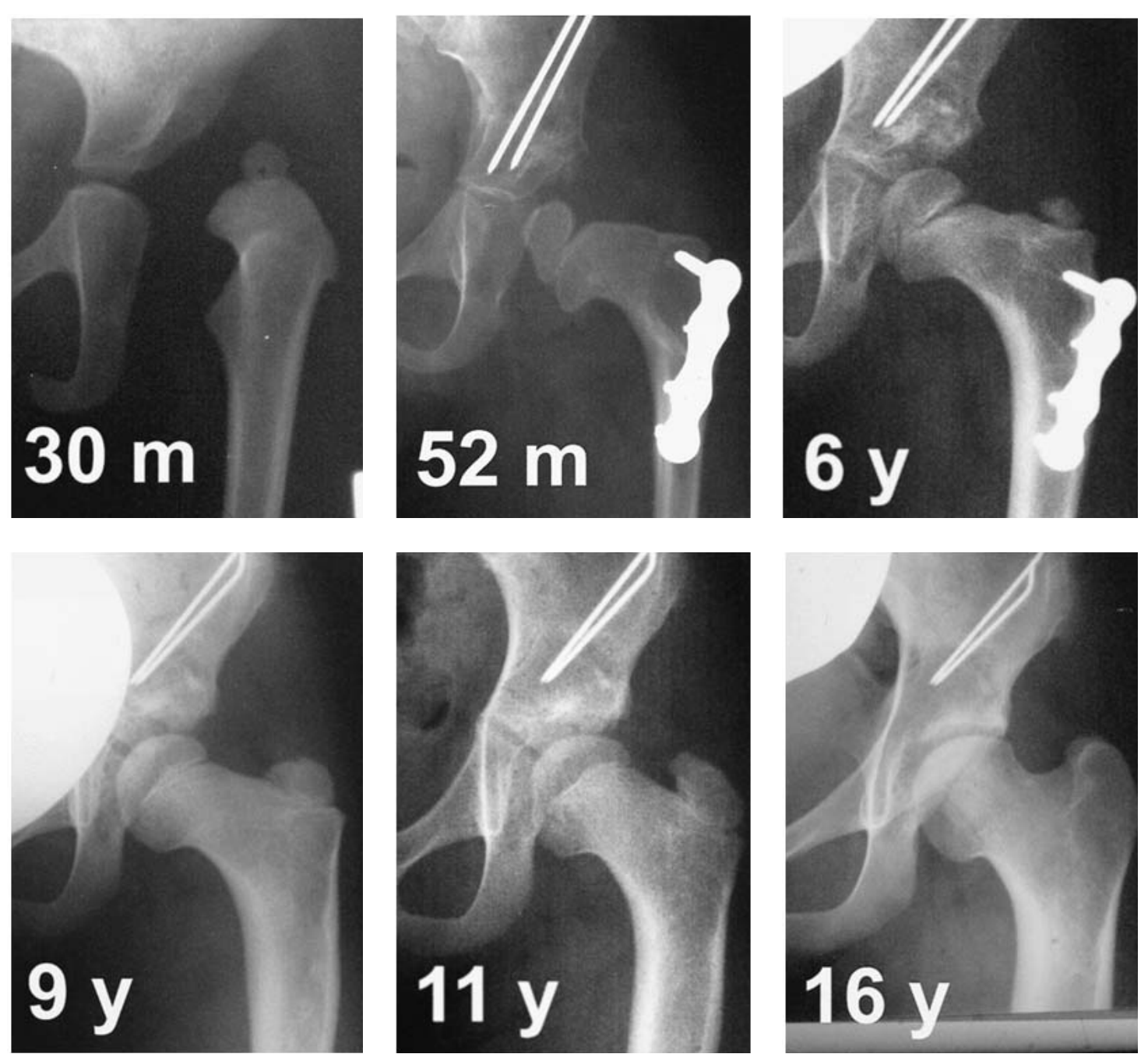

Fig. 4

Serial radiographs of a 30-month-old girl who presented with bilateral DDH. She was treated by bilateral open reduction and innominate and upper femoral shortening osteotomies. Early radiographs of the left hip show no evidence of AVN. At 11 years of age early features of central physeal tethering and growth arrest are present on the left side. Radiographs at skeletal maturity show coxa brevis. The joint dysplasia was graded as Severin group II.

done at the time of the open reduction or two to four weeks later and not at a later stage when recurrent subluxation is occurring. Seven of the 95 hips have required further surgery for persistent dysplasia. One of the main advantages of achieving a stable reduction in the position of weight-bearing at the time of open reduction is that prolonged immobilisation in a cast is unnecessary. No orthosis is required and the child can be mobilised as soon as the soft tissues have healed and the osteotomies united.

It has been the senior author's (AC) experience that in a significant number of cases the test of stability has shown a stable reduction in two different positions; internal rotation with abduction and flexion with abduction. In this situation we have usually carried out a derotational femoral osteotomy since we felt that the primary deformity was femoral anteversion. Of hips treated by open reduction and femoral osteotomy, $90 \%$ achieved a satisfactory radiological result. In this situation the surgeon also has the choice of carrying out an innominate osteotomy to achieve a stable reduction, as both derotational femoral osteotomy and innominate osteotomy have the effect of directing the femoral head posteriorly.

When flexion is specifically required for stability we feel that an innominate osteotomy should be undertaken. The flexion element should always be removed first when carrying out the test of stability in order to identify this. If a hip only requires internal rotation for stability, a derotational osteotomy is indicated. An innominate osteotomy in this type of hip may result in a posterior dislocation since the major problem is one of femoral anteversion. ${ }^{11}$

There is currently a vogue for open reduction carried out by a medial approach in the first few months of life. ${ }^{12,13}$ In our series open reduction was deliberately delayed until about one year. The results have been acceptable (Severin I and II) in $94 \%$ of hips when this procedure was carried out in children under the age of two years. They compare 

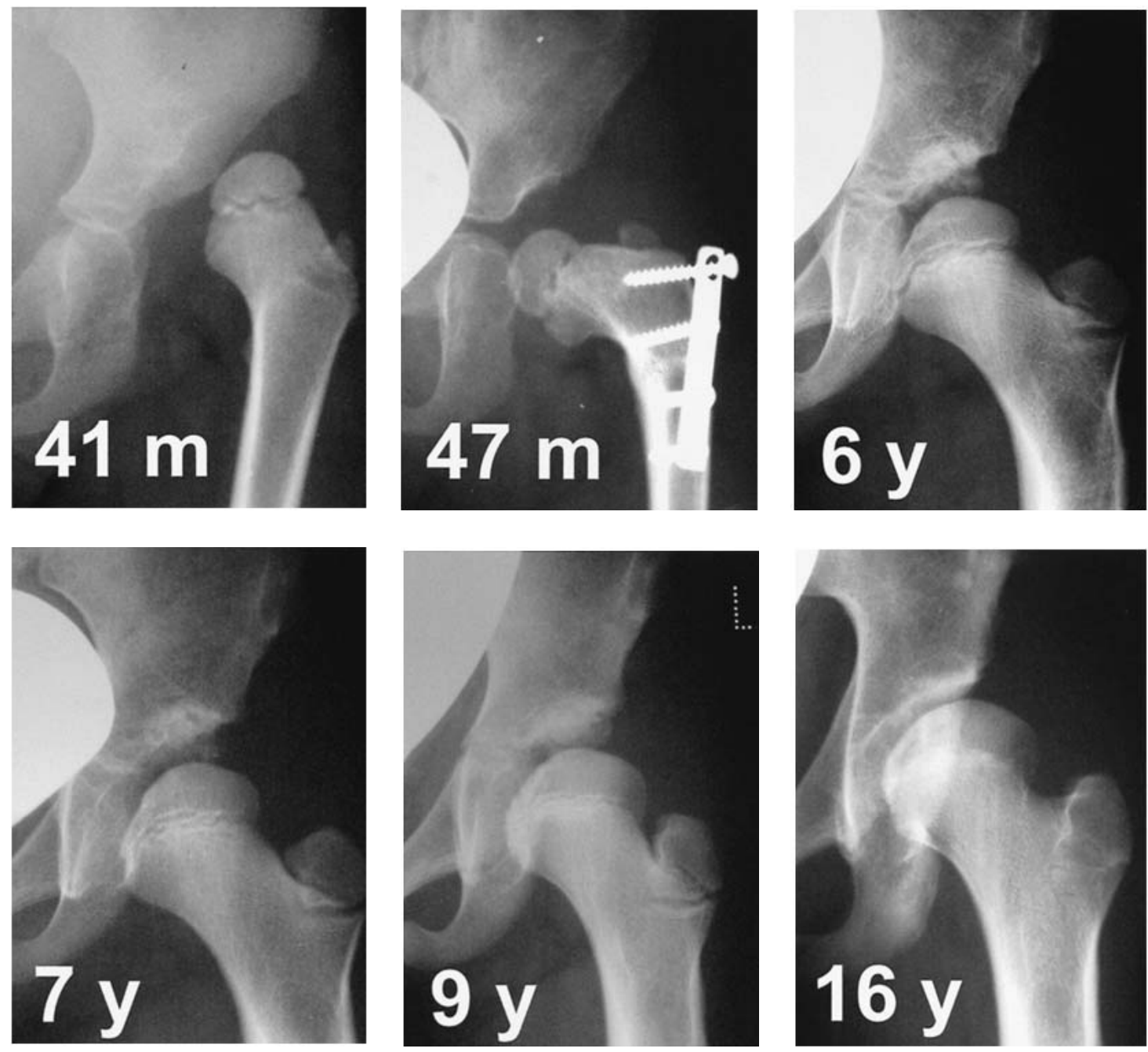

Fig. 5

Serial radiographs of a 41-month-old girl who presented with unilateral left DDH. She was treated by an open reduction and upper femoral varus and derotational osteotomy. Early radiographs show no definite evidence of AVN. Radiographs at nine years of age show early features of lateral physeal tethering and growth arrest. Although the radiographs at skeletal maturity do not show joint subluxation, the combination of coxa magna and valgus has resulted in the recurrence of joint dysplasia (centre-edge angle less than $20^{\circ}$ ). This hip has been graded as Severin group III.

Table VIII. Postoperative complications, excluding AVN and premature physeal arrest. Some hips had more than one complication

\begin{tabular}{lll}
\hline Complication & $\begin{array}{l}\text { Number of } \\
\text { hips }\end{array}$ & $\begin{array}{l}\text { Number of hips requiring } \\
\text { surgical intervention }\end{array}$ \\
\hline Recurrent dysplasia (Severin groups III and IV) & $13^{*}$ & 7 \\
Redislocation & 1 & 1 \\
Long leg $>1.5 \mathrm{~cm}$ (long-leg dysplasia) & 12 & 4 \\
Short leg $>1.5 \mathrm{~cm}$ & 2 & 1 \\
Infection & 2 & 2 \\
Meralgia paraesthetica & 3 & 2 \\
Intermittent pain & $7 \dagger$ & 3 \\
Distal femoral greenstick fracture & 8 & - \\
Trendelenberg gait & 4 & 3 \\
\hline
\end{tabular}

* five hips had associated long-leg dysplasia

$\dagger$ three hips had an associated Trendelenberg gait 

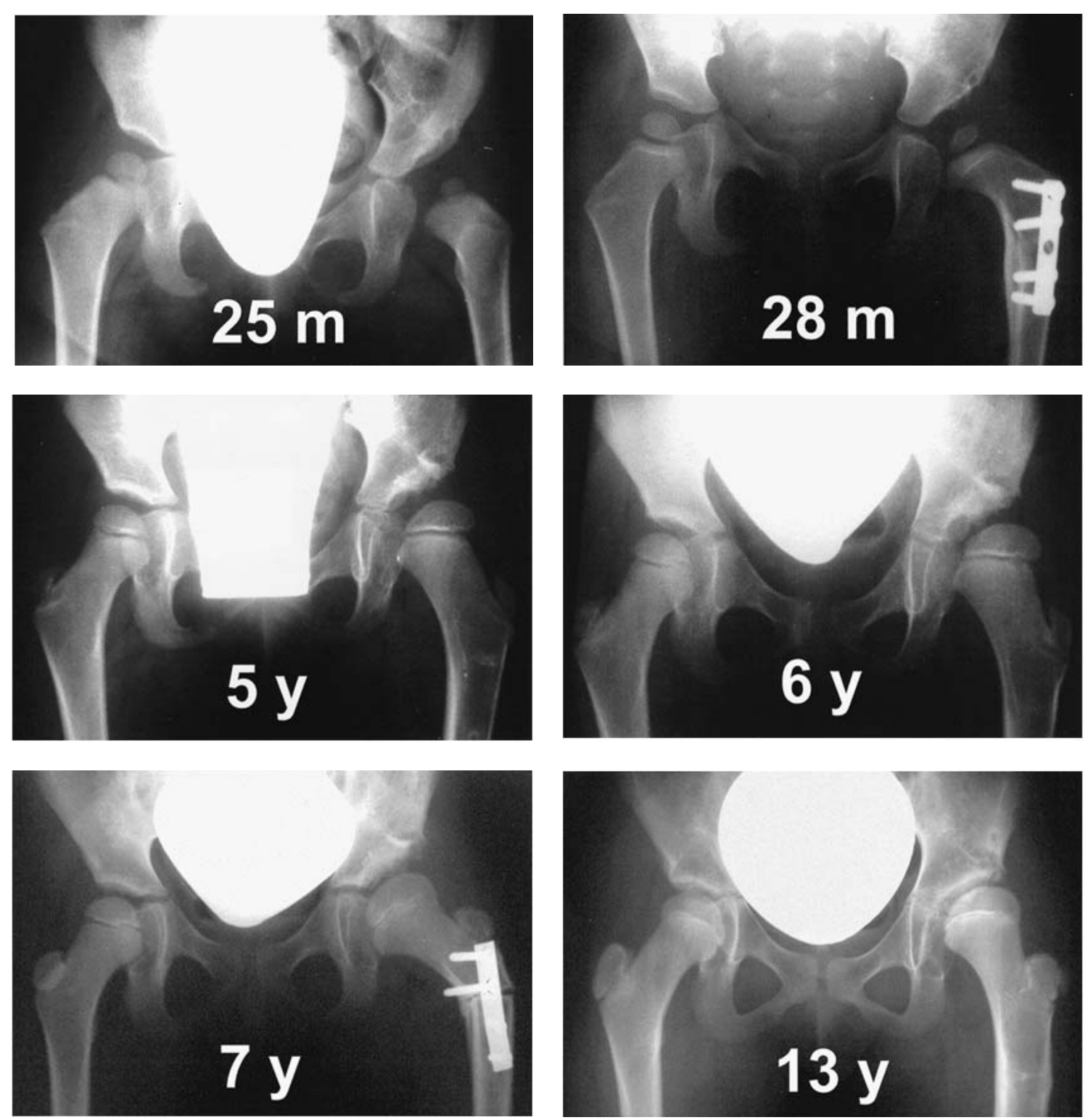

Fig. 6

Radiographs of a 25-month-old girl who presented with unilateral DDH. She was treated by an open reduction and upper femoral varus and derotational osteotomy. Early postoperative radiographs show no evidence of AVN. At the age of five years the affected leg is $2 \mathrm{~cm}$ longer. Radiographs show coxa valga with excessive femoral anteversion and a sloping acetabulum (long-leg dysplasia). These features did not resolve spontaneously and at the age of seven years she was treated by a further upper femoral varus and derotational osteotomy. With subsequent growth these dysplastic features have again recurred and the joint dysplasia has been graded as Severin group IV.

favourably with the results of open reduction with a medial approach. It could therefore be argued that when open reduction is required the operation is best delayed until the child is about one year old.

Analysis of our unsatisfactory radiological results has shown that most cases have been associated with long-leg dysplasia $(p=0.01)$, AVN or premature physeal arrest $(\mathrm{p}=0.01)$. Other factors include late presentation $(\mathrm{p}=0.04)$ and a Pemberton osteotomy. Seven hips required surgery for correction of recurrent dysplasia. In four we believe that the main cause was long-leg dysplasia and in two AVN resulting in coxa magna and valga. One hip redislocated, probably due to the inappropriate selection of an innominate osteotomy after open reduction in an older child with a severely dysplastic acetabulum and subluxation. In retrospect, a Pemberton osteotomy would have been a more appropriate choice.

The incidence of AVN and premature physeal arrest in our series is similar to that in other studies ${ }^{6,7,9,12-21}$ It remains a cause for concern. These complications may result in upper femoral deformities such as coxa magna, valga or brevis and were more common in high dislocations $(\mathrm{p}=0.04)$. Although in most cases the acetabulum remodels to accommodate for these deformities, in a number of 
Table IX. Results of other long-term studies for DDH treated by open reduction

\begin{tabular}{|c|c|c|c|c|c|c|c|}
\hline Author/s & $\begin{array}{l}\text { Type of } \\
\text { surgery* }\end{array}$ & $\begin{array}{l}\text { Number } \\
\text { of hips }\end{array}$ & $\begin{array}{l}\text { Mean follow-up } \\
\text { (yr) }\end{array}$ & $\begin{array}{l}\text { Severin } \\
\text { I and II } \\
(\%)\end{array}$ & $\begin{array}{l}\text { AVN } \\
(\%)\end{array}$ & $\begin{array}{l}\text { Secondary surgery } \\
\text { for dysplasia } \\
(\%)\end{array}$ & $\begin{array}{l}\text { Redislocation } \\
(\%)\end{array}$ \\
\hline Gibson and Benson ${ }^{9}$ & $\begin{array}{l}\text { Limbectomy } \dagger \\
+\mathrm{FO}\end{array}$ & 147 & 22 & 47 & 5 & 39 & 1 \\
\hline \multirow[t]{2}{*}{ Williamson et $\mathrm{al}^{17}$} & $\begin{array}{l}\text { Limbectomy } \dagger \\
+\mathrm{FO}\end{array}$ & 34 & 17 & 41 & 12 & 41 & 0 \\
\hline & $\mathrm{AOR}+\mathrm{IO}$ & 11 & 11 & 82 & 9 & 0 & 0 \\
\hline Gulman et $\mathrm{al}^{18}$ & $\mathrm{AOR}+\mathrm{IO}$ & 52 & 13 & 71 & 63 & & \\
\hline Barrett et $\mathrm{al}^{19}$ & $\mathrm{AOR}+\mathrm{IO}$ & 15 & 11 & 74 & 13 & 18 & 7 \\
\hline Klisic and Jakovic $^{20}$ & $\begin{array}{l}\mathrm{AOR}+\mathrm{FS} \\
\pm \mathrm{PO}\end{array}$ & 60 & $7 \ddagger$ & 58 & 28 & 7 & 2 \\
\hline Morcuende et $\mathrm{al}^{13}$ & MOR & 93 & 10 & 71 & 43 & 17 & 2 \\
\hline Koizumi et $\mathrm{al}^{12}$ & MOR & 35 & 19 & 46 & 43 & 46 & 0 \\
\hline This series & $\begin{array}{l}\mathrm{AOR} \pm \mathrm{FO} \\
\pm \mathrm{PO}\end{array}$ & 95 & 15 & 86 & $7+18$ & 7 & 1 \\
\hline
\end{tabular}

* AOR, anterior open reduction; MOR, medial open reduction; FO, femoral osteotomy; FS, femoral shortening; IO, innominate osteotomy; PO, pelvic osteotomy

$\dagger$ minority of cases had a closed reduction instead of limbectomy

$\ddagger$ most patients were skeletally mature at the latest follow-up

our patients the remodelling process was inadequate, resulting in the recurrence of joint dysplasia (Fig. 5). ${ }^{12-15}$ Almost all type-II and type-III deformities of Kalamchi and MacEwen presented as premature physeal arrest at the time of the adolescent growth spurt and were not apparent on the earlier radiographs (Figs 3 to 5). This has also been highlighted in a number of recent articles. ${ }^{3,12,13,15}$ Koizumi et $\mathrm{al}^{12}$ in a long-term review of 35 patients with DDH treated by open reduction through a medial approach, noted a rate of AVN of $43 \%$. Most of these cases presented as Kalamchi-MacEwen type-II deformity after the age of ten years and were associated with recurrence of joint dysplasia. Morcuende et al, ${ }^{13}$ in a similar study, reported that most of their cases of Bucholz-Ogden type-II $\mathrm{AVN}^{22}$ (similar to Kalamchi-MacEwen type II) presented late. They commented that: "Rates of growth disturbances at less than ten years' follow-up must be regarded as preliminary findings and may not reflect the true prevalence of these lesions". We believe that studies with a relatively short follow-up will significantly overestimate the proportion of good radiological results, ${ }^{9,12,17}$ and surveillance until skeletal maturity is therefore recommended.

It has been suggested that one of the causes of type-II AVN may be immobilisation in a cast in excessive abduction resulting in impaction of the acetabular labrum on the lateral capital femoral physis. ${ }^{13,16}$ By observing a meticulous surgical technique, avoiding extreme positions during immobilisation in a cast and more liberal use of femoral shortening ${ }^{1,6,21}$ at the time of open reduction, the incidence of AVN and premature physeal arrest can be kept to a minimum.

Long-leg dysplasia, which was first described by Mitch$\mathrm{ell}^{23}$ and later discussed by Catterall, ${ }^{24}$ may be an important cause of the recurrence of joint dysplasia (Fig. 6). In this condition, to accommodate for the leg-length discrepancy, the affected leg becomes adducted in the position of weight-bearing. This may then result in excessive loading of the superolateral acetabular margin and the labrum. In some hips this will inhibit the normal development of the lateral acetabular epiphysis resulting in a shallow or sloping acetabulum. We attempted to treat this condition by a varus and shortening femoral osteotomy. This was generally unsuccessful in completely reversing the dysplastic features in the long term, especially when the acetabulum was already sloping and joint subluxation present (Fig. 6). There is little potential for remodelling in the acetabulum of an older child. ${ }^{15}$ To correct long-leg dysplasia the abnormalities on both sides of the joint should be addressed.

In our experience, the results after a Pemberton osteotomy have been unpredictable. Despite achieving a satisfactory reduction and coverage of the femoral head at the initial operation, the acetabulum failed to develop adequately with subsequent growth in two out of four of our hips, and joint dysplasia recurred. This may be due to inadvertent injury to the lateral acetabular epiphysis during the operation.

Table IX lists the results of a number of long-term studies. $^{9,12,13,17-20}$ We have avoided a direct comparison between our data and these series. Differences in referral patterns, patient selection, operative techniques, length of follow-up, criteria for secondary surgery and poor interobserver reliability of the radiological classification systems $^{25}$ make such comparisons of limited value. In our series the rate of revision for persistent dysplasia and redislocation has been acceptably low and, in most hips, a satisfactory outcome has been achieved.

We find the test of stability as described a useful and reliable means of assessing the need for a pelvic or femoral osteotomy at the same time as an open reduction for DDH. So far only seven hips have required revision. The incidence of postoperative AVN of 7\% and of premature physeal closure of $18 \%$ may, however, lead to significant risk of premature osteoarthritis in adult life.

No benefits in any form have been received or will be received from a commercial party related directly or indirectly to the subject of this article. 


\section{References}

1. Tönnis D. Nomenclature and classification of congenital hip dislocation. In:Tönnis D, ed. Congenital dysplasia and dislocation of the hip in children and adults. Berlin, etc: Springer-Verlag, 1987:80-3.

2. Severin E. Contribution to knowledge of congenital dislocation of hip joint: late results of closed reduction and arthrographic studies of recent cases. Acta Chir Scand 1941 [Suppl 63];84;1-142.

3. Kalamchi A, MacEwen GD. Avascular necrosis following treatment of congenital dislocation of the hip. J Bone Joint Surg [Am] 1980; 62-A:876-88.

4. Catterall A. Operations for congenital dislocation of the hip. In: Bentley G, Greer RB III, eds. Rob and Smith's operative surgery: orthopaedics. Fourth edition, London: Chapman and Hall Medical, 1991:870-92.

5. Catterall A. A colour atlas of open reduction of a congenital dislocation of the hip. Single surgical procedures series; Vol. 35, London: Wolfe Medical Publications Ltd, 1986:5-62.

6. Tönnis D. Surgical treatment of congenital dislocation of the hip. Clin Orthop 1990;258:33-40.

7. Salter RB, Dubos JP. The first fifteen years' personal experience with innominate osteotomy in the treatment of congenital dislocation and subluxation of the hip. Clin Orthop 1974;98:72-103.

8. Pemberton PA. Pericapsular osteotomy of the ilium for treatment of congenital subluxation and dislocation of the hip. J Bone Joint Surg [Am] 1965;47-A:65-86.

9. Gibson PH, Benson MKD. Congenital dislocation of the hip: review at maturity of 147 hips treated by excision of the limbus and derotation osteotomy. J Bone Joint Surg [Br] 1982;64-B:169-75.

10. Harris NH, Lloyd-Roberts GC, Gallien R. Acetabular development in congenital dislocation of the hip: with special reference to the indications for acetabuloplasty and pelvic or femoral realignment osteotomy. J Bone Joint Surg [Br] 1975;57-B:46-52.

11. Fixsen JA. Anterior and posterior subluxation of the hip following innominate osteotomy. J Bone Joint Surg [Br] 1987;69-B:361-4.

12. Koizumi W, Moriya H, Tsuchiya K, et al. Ludloff's medial approach for open reduction of congenital dislocation of the hip: a 20-year follow-up. J Bone Joint Surg [Br] 1996;78-B:924-9.

13. Morcuende JA, Meyer MD, Dolan LA, Weinstein SL. Long-term outcome after open reduction through an anteromedial approach for congenital dislocation of the hip. J Bone Joint Surg [Am] 1997;79-A: 810-7.
14. Imatani J, Miyake Y, Nakatsuka Y, Akazawa H, Mitani S. Coxa magna after open reduction for developmental dislocation of the hip. $J$ Pediatr Orthop 1995;15:337-41.

15. Mardam-Bey TH, MacEwen GD. Congenital hip dislocation after walking age. J Pediatr Orthop 1982;2:478-86.

16. Campbell P, Tarlow SD. Lateral tethering of the proximal femoral physis complicating the treatment of congenital hip dysplasia. $J$ Pediatr Orthop 1990;10:6-8.

17. Williamson DM, Glover SD, Benson MKD. Congenital dislocation of the hip presenting after the age of three years: a long-term review. J Bone Joint Surg [Br] 1989;71-B:745-51.

18. Gulman B, Tuncay IC, Dabak N, Karaismailoglu N. Salter's innominate osteotomy in the treatment of congenital hip dislocation: a long-term review. J Pediatr Orthop 1994;14:662-6.

19. Barrett WP, Staheli LT, Chew DE. The effectiveness of the Salter innominate osteotomy in the treatment of congenital dislocation of the hip. J Bone Joint Surg [Am] 1986;68-A:79-87.

20. Klisic P, Jankovic L. Combined procedure of open reduction and shortening of the femur in treatment of congenital dislocation of the hips in older children. Clin Orthop 1976;119:60-9.

21. Schoenecker PL, Strecker WB. Congenital dislocation of the hip in children: comparison of the effects of femoral shortening and of skeletal traction in treatment. J Bone Joint Surg [Am] 1984;66-A: 21-7.

22. Bucholz RW, Ogden JA. Patterns of ischaemic necrosis of the proximal femur in nonoperatively treated congenital hip disease. In: The Hip. Procs of the 6th meeting of the Hip Society, 1978. St. Louis, etc: CV Mosby Co, 1978:43-63.

23. Mitchell GP. Late congenital dislocation of the hip. Rev Chir Orthop Reparatrice Appar Mot 1981;67:241-7.

24. Catterall A. Assessment of adolescent acetabular dysplasia. In: Catterall A, ed. Recent advances in orthopaedics. Number 6. Edinburgh: Churchill Livingstone, 1992:103-18.

25. Ward WT, Vogt M, Grudziak JS, et al. Severin classification system for evaluation of the results of operative treatment of congenital dislocation of the hip: a study of intraobserver and interobserver reliability. J Bone Joint Surg [Äm] 1997;79-A:656-63. 